\title{
Facilitated propylene transport in mixed matrix membranes containing ZIF-8@Agmim core-shell hybrid material
}

\author{
Xiaoquan Feng ${ }^{1}$, Donglai Peng ${ }^{2}$, Meixia Shan $^{1}$, Xinpu Niu ${ }^{1}$, and Ya-Tao Zhang ${ }^{3}$ \\ ${ }^{1}$ Affiliation not available \\ ${ }^{2}$ Zhengzhou University of Light Industry \\ ${ }^{3}$ Zhengzhou University
}

October 18, 2021

\begin{abstract}
The ZIF-8@Agmim core-shell hybrid material was synthesized via a favorable post-modification method of ion exchange (PMIE). This infrequent ZIF-8@Agmim core-shell structure maintains a well- integrated pore size that is almost the same as ZIF-8. The similar equilibrium isotherms with ZIF-8 and better kinetic separation towards propylene/propane than ZIF-8 render ZIF$8 @$ Agmim to be an interesting candidate for propylene/propane separation. The core-shell hybrid nanomaterial was further used as nanofillers in the polymer of intrinsic microporosity matrix (PIM-1) for propylene/propane separation. The resultant MMMs exhibited a simultaneous increase in $\mathrm{C} 3 \mathrm{H} 6$ permeability and $\mathrm{C} 3 \mathrm{H} 6 / \mathrm{C} 3 \mathrm{H} 8$ ideal selectivity compared to pure polymer membrane owing to a synergistic effect of molecular sieving from ZIF-8 and $\pi$-complexation of Ag+ with propylene. The separation performance of the prepared MMM surpasses the upper bound line of polymer membranes. Furthermore, the hybrid materials possess superb photochemical stability and the corresponding MMMs exhibit excellent anti-aging property and long-term stability.
\end{abstract}

\section{Hosted file}

Manuscript-ZIF-8@Agmim-AICHE.docx available at https://authorea.com/users/441547/articles/ 542030-facilitated-propylene-transport-in-mixed-matrix-membranes-containing-zif-8-agmimcore-shell-hybrid-material

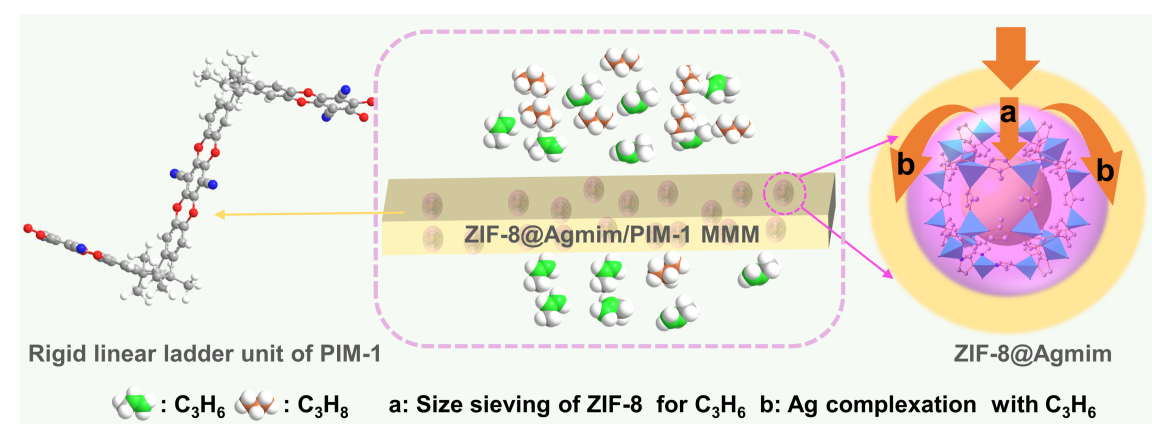

